\title{
ACM Multimedia 2013 (ACM MM '13) レポート
}

\section{(正会員)山崎 俊 彦}

本稿は，2013年10月 21 日から 25 日まで，スペイン・バルセロナで開催された第 21 回 ACM Multimedia 2013 会議の様子を報告するものである。ACM Multimediaはマルチメディア分野では最高峰の国際会議の 一つであり，最先端技術の研究発表はもちろん，さまざまなマルチメディアに関するイベントがあること も特徴である。

キーワード：ACM Multimedia, マルチメディア, コンピュータビジョン, 画像処理, アート

\section{1.まえがき}

本会議は, Association of Computing Machinery (ACM)の 分科会Special Interest Group in Multimedia (SIGMM) が主 催するフラッグシップ会議であり，今回は21回目を迎えた。 昨年は奈良で開催されたのでご記憶の方も多いだろう.

ACM には本原稿執筆段階で 36 の分科会 $(\mathrm{SIG})$ があり ${ }^{1)}$, SIGMM は比較的大きな SIGの一つである。ちなみに, 蛇 足ではあるが ACM の SIGの中でダントツに会員数が多い のはSIGGRAPHである.

本年の ACM Multimedia本会議は, スペイン・バルセロ ナのCentre de Convencions Internacional de Barcelona と いう会議場で開催された。旧市街地からは地下鉄で $20 ３ 0$ 分のところにあり，海に面した落ち着いた雲囲気の会場で ある(図1). 少し歩いたところにはマリーナやビーチなど もあった。

本稿では，2章で会議の概要，3章で 2013 年の研究動向な どを紹介し，4章では今年・来年の開催地の紹介をする.

\section{ACM Multimediaの概要}

\subsection{Long Paper and Short Paper}

今年の ACM Multimediaは下記に示す 12 の分野がもうけ られ，29名のエリアチェアが論文のハンドリングを行った.

(1) Art, Entertainment and Culture

(2) Authoring and Collaboration

(3) Crowdsourcing

(4) Media Transport and Delivery

(5) Mobile \& Multi-device

(6) Multimedia Analysis

†東京大学 大学院情報理工学系研究科 電子情報学専攻

"ACM Multimedia 2013 (ACM MM '13) Report" by Toshihiko Yamasaki (Department of Information and Communication Engineering, Graduate School of Information Science and Technology, The University of Tokyo, Tokyo)

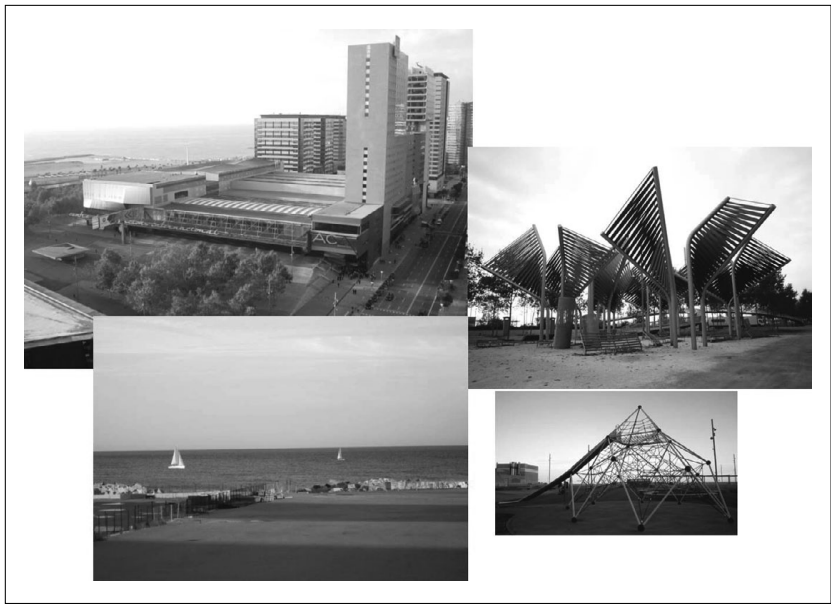

図 1 会議場と周辺の様子(写真提供：Ms. Litian Sun)

(7) Multimedia HCI

(8) Music \& Audio

(9) Search, Browsing and Discovery

(10) Security and Forensics

(11) Social Media \& Presence

(12) Systems and Middleware

ACM Multimedia 2012でもうけられたテーマは下記の 11 個だった。

(1) Media Content Analysis and Processing

(2) Multimedia Activity and Event Understanding

(3) Multimedia Search and Retrieval

(4) Mobile and Location-Based Media

(5) Social Media

(6) Multimedia Systems and Middleware

(7) Media Transport and Sharing

(8) Multimedia Security and Forensics

(9) Multimedia Authoring, Production and Consumption

(10) Multimedia Interaction and Applications

(11) Multimedia Art, Entertainment and Culture

見比べてみると, Crowdsourcingが追加されたりテーマ 


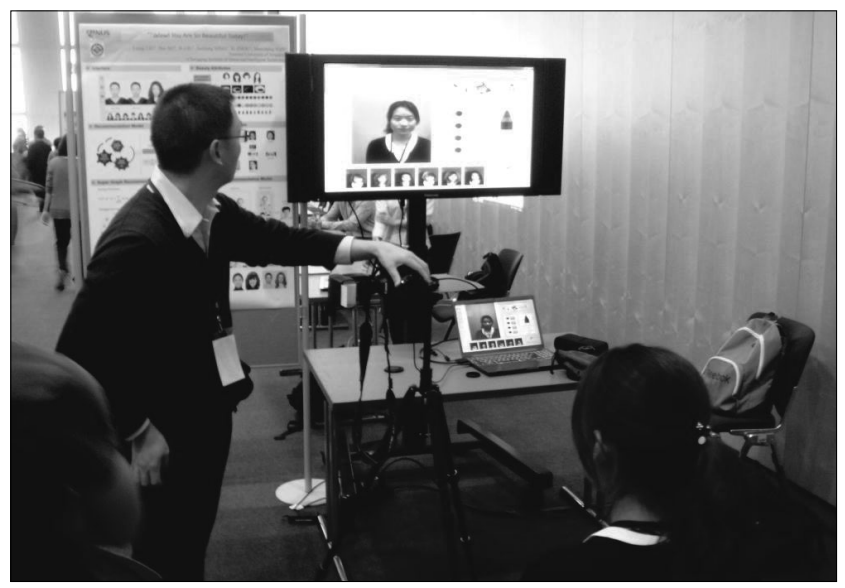

図2『Wow! You Are So Beautiful Today!』のデモでヘアスタイ ルとメイク推薦を受ける女性

の表現に微妙な違いが見られたりしており，1年間でのこ の分野のトレンドの変化が見て取れる.

論文の投稿数はLong Paper, Short Paperそれぞれに

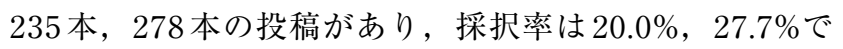
あった．採択率は昨年度とほとんど変わらないといえる。

オーラル発表 (Long Paper) は11のセッションで発表が あり, 最大で 2 並列のセッション, そのほかのイベントを 含めても最大 3 並列のセッションまでにとどまるように工 夫がなされていた。また，ポス夕 (Short Paper) \&デモは オーラルと重ならないように専用の時間帯がもうけられて いたため，例年に比べて「聞き逃した感」が少なかったよう に思う。

\subsection{Art Exhibition and Demo}

ACM Multimediaの大きな特徵は, Multimedia Art

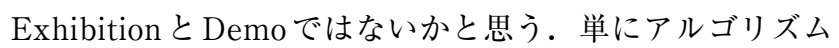
の話をするだけでなくインタラクティブ性を重視し, 動い てなんぼ，さわれてなんほ，というのがマルチメディアら しさを表している.

Art Exhibitionは, 10月21日から28日までFoment de les Arts i Del Disseny (FAD) 開催され，10件の展示が あった，筆者はずっと本会議場にいたこともあり，残念な がら Art Exhibitionに参加することはできなかった.

Demoは 2 日目と 3 日目それぞれ 20 件, 合計 40 件もの出 展があった. ほかの国際会議では, デモはあっても数件程 度のことが多いが, ACM Multimediaではシステムを実際 に触って体験できることを重要視していることがうかがえ る. また，充分なスペースが設けられ，じっくりとデモを 体験したり，デモ展示者らとデイスカッションしたりする ことが可能であった．図2に示すのは, Best Paper Award もとった『Wow! You Are So Beautiful Today!』のデモの 様子である.

\subsection{Tutorials and Workshops}

チュートリアルとワークショップは同じ枠で開催され， 本会議前日の 2 日間をかけて行われた。予算の都合上，本 会議場ではなく, 旧市街地近くの小さな会場 (Universitat Pompeu Fabra) で行われたこともあり, どの会場もいっぱ
いで盛況感があった。多くのチュートリアル・ワーク ショップに socialやlarge-scale，またはそれらを想起させ るキーワードが多数含まれている点が，ここ数年のマルチ メディア研究の趨勢を反映していると言えよう.

【チュートリアル】

(1) Blending the Physical and the Virtual in Music Technology: from Interface Design to Multi-modal Signal Processing

(2) Crowdsourcing for Multimedia Research

(3) Massive-Scale Multimedia Semantic Modeling

(4) Privacy Concerns of Sharing Multimedia in Social Networks

(5) Social Interactions over Geographic-Aware Multimedia Systems

(6) Multimedia Information Retrieval: Music and Audio 【ワークショップ】

(1) ACM Multimedia Workshop on Geotagging and Its Applications

(2) 5 th International Workshop on Multimedia for Cooking and Eating Activities (CEA2013)

(3) 4 th ACM/IEEE ARTEMIS 2013 International Workshop on Analysis and Retrieval of Tracked Events and Motion in Imagery Streams

(4) 2 nd International Workshop on Socially-Aware Multimedia

(5) Data-driven challenge-based workshop (AVEC 2013)

(6) 3rd International Workshop on Interactive Multimedia on Mobile and Portable Devices (IMMPD '13)

(7) 2 nd ACM International Workshop on Multimedia Analysis for Ecological Data (MAED 2013)

(8) International ACM Workshop on Crowdsourcing for Multimedia (CrowdMM 2013)

(9) Personal Data Meets Distributed Multimedia

(10) First ACM MM Workshop on Multimedia Indexing and Information Retrieval for Healthcare (ACM MM MIIRH)

(11) 4 th International Workshop on Human Behavior Understanding (HBU)

(12) Immersive Media Experiences

\subsection{Keynotesなど}

初日は, Dr. Elizabeth F. Churchill(eBay Research Labs) による"Multimedia Framed", 2 日目はProf. Leonidas J. Guibas (Stanford University)による"The Space Between the Images"という題目のキーノートスピーチがなされた.

3日目はキーノートではなく, Technical achievement award受賞者の Dr. Dick Bulterman (FAPAL) による講演 がなされた。

\section{5 その他のイベント}

グランドチャレンジは，さまざまな企業が大まかな問題 
意識の設定とデータの提供を行い, 参加者がその問題に対 する解決策を提案する, というイベントである. 示された 問題意識の中で, どのような問題設定をし, どうやってそ の問題を解くかというところまで参加者が自由に設定して よいものがほとんどである。したがって，通常のコンテス 卜に見られるように，厳密に問題や条件が決まっていて参 加者同士で性能を競い合うのとは趣が異なっている. 今年 は下記の6件のグランドチャレンジに対し，14件の発表が あった。受賞者については文献2) を参照されたい.

グランドチャレンジの課題リストを下記に示す. NHKか ら提案された「Where is beauty?」はNHK の映像素材 1000 本を対象に動画の審美評価を行うという課題である．私が 日本人だから NHKになじみが深いということもあろうが, このチャレンジは後々まで学会参加者の話題の種になって いたように思う。

(1) NHK - Where is beauty? Grand Challenge

(2) Technicolor - Rich Multimedia Retrieval from Input Videos Grand Challenge

(3) Yahoo! - Large-scale Flickr-tag Image Classification Grand Challenge

(4) Huawei/3DLife - 3D human reconstruction and action recognition Grand Challenge

(5) MediaMixer/VideoLectures.NET - Temporal Segmentation and Annotation Grand Challenge

(6) Microsoft: MSR - Bing Image Retrieval Grand Challenge

そのほか, Ph. D.コースの学生を対象としたDoctoral symposium やパネルディスカッションなど意欲的なイベン トも行われた.

あともう一つ，強調して紹介しておきたいのがPh. D. Thesis Award ${ }^{4)}$ である.これは (今回であれば2012年の) 1月 から 12 月までに発表されたマルチメデイア研究に関連する 博士論文が審査対象になり，1件の優秀賞を選ぶというも のであり，ACM Multimediaで表彰式がある.さらに，シ ングルセッションで発表する機会が与えられる．来年度も 開催されるということなので，日本国内で博士を取得され る方はチャレンジしていただきたい.

\section{6 新たな試み}

今年はLong Paperの查読について新しい試みがなされ た. 査読者の (否定的な) コメントや誤解に対して反論する 機会が与えられる Rebuttalに加え, 査読者から不当に評価 を得ていると感じられたときに別の査読者を要求する Advocateという制度が導入された。16本の論文が Advocateを申請し, そのうち5件が認められたということ である.

一方，例年はShort Paperの締め切り日がLong Paperよ りも遅く設定されているのに対し, 今年は同じであったこ とが反省点としてあげられていた. 来年以降は改善される であろう。

ほかの国際会議でも同様の試みが最近みられるように
なったが，モバイル用プログラムが提供された．MITの CSAILが開発したConfer Online Program System ${ }^{3)}$ を利用 したもので，ユーザがお気に入り論文を登録すると，その 他のおすす論文を紹介してくれる．自分が興味を持つ論 文を取りこぼしなく聴講することができるという優れもの である，ただし，会場は必ずしもインターネット環境がい いとは言えず，このシステムがどこまで役に立っていたか は未知数である.

ほかに面白いと思ったのは，Women Lunch という女性 研究者限定のランチ会である.マルチメディアは今年の Best Paperがヘアスタイルとメイクの推薦システムであっ たことに象徴されるように，いわゆる「ゆるふわ」な研究も 切り口や見せ方次第で高く評価される分野であり，女性視 点の柔軟な発想が今後も大いに期待される.

\section{3. 研究動向}

まずは論文賞から紹介していきたい，なお，受賞論文の 詳細はACM Multimediaのサイトに記載されている2). Best Paperセッションは初日の午前行われ，審査対象とな る4件の研究成果発表があった. Best Paper Awardには National University of SingaporeのLuoqi Liu氏らによる "Wow! You Are So Beautiful Today!"が選ばれた.「『今日 は』ではなく，『今日も』といわないと駄目だな...」などと いう突っ込みはさておき，本論文は近年流行している Attributeの概念を，美容を表現する特徴量に導入し， スーパーグラフによって美容パラメータ同士の関係性を記 述して, 最適化問題に落とし込むことでへアスタイルとメ イクの推薦を実現している。このグループはこれまでにも ファッション(衣服)の認識など野心的な発表を行っている.

Best Student Paper Awardは, 同じくNational University of Singaporeの Hanwang Zhang氏らによる "Attributes-augmented Semantic Hierarchy for Image Retrieval"が選ばれた。

それ以外の論文については，読者ごとに興味をお持ちの 分野が異なるであろうから網羅的には紹介しないが，個人 的な印象として，コンピュータビジョンやパターン認識系 の学会で発表される論文と境界が薄くなってきている気が する. 最近流行の AttributeやLatent SVMなど，中間的特 徵表現・潜在変数を使った研究も多く目についた。逆に， 大規模画像検索やシステム論文などこれまでの ACM MM の定番トピックが少なかったように思う.

筆者の独断と偏見で興味を持ったものをあげると，ス マートフォンなどの携帯端末でいかに効率よくかつ正確に 画像認識や検索を行うかといった課題が何件か扱われてい た。スマートフォン時代になって，アプリをインストール すればさまざまなことができるようになったが，画像・映 像を扱㧍うとすると，やはり処理コストやデー夕転送が ネックになる。それをどううまく解決するかについては今 後も重要な課題になるのではないか. 数年前から画像・映 像の審美評価が流行しているが，NHKのグランドチャレ 
ンジでの数件の発表に加えて, 提示される画像の大きさと 主観評価の関係について大規模実験をした論文もあり, 興 味深かった.また, Kinnectなど奥行きセンサが普及した 影響もあり，行動認識の発表も目立っていた.

\section{4. 開催地の紹介}

このような国際会議報告では, 開催地の魅力までお伝え することはまれであるように思う。また，諸先輩方から 「国際会議参加は遊びに行っているのではない」と叱咤され そうであるが，行ったことのない国や街に行くというのは 心躍るものであるし, 開催地の魅力が論文を出すモチベー ションになることもあるのも事実である，そこで，本年と 来年の開催地について簡単にご紹介したい.

\section{1 スペイン・バルセロナ}

バルセロナはカタルーニャ州の州都であり, 首都マド リードに次ぐ第 2 の規模の都市である. バルセロナといえ ばガウディが 2 代目建築家として設計・指揮したサグラ ダ・ファミリアが最も有名である。2005年には世界遺産に 登録されている. サグラダ・ファミリアは 1882 年 (明治 15 年!) の建築開始以来,「ずっと建築中」というイメージが ある。しかし，実は 2011 年に内装が完成し，中に入れば外 の工事の様子などみじんも感じさせない荘厳な䨌囲気を感 じることができる (図3). また, 3Dプリンタによる技術革 新のおかげで完成予定が前倒しになり, ガウディの没後 100 年にあたる 2026 年には完成予定だそうである. 最近話 題の $3 \mathrm{D}$ プリンタであるが，こんなところでも活躍してい るとは, 大変興味深い. そのほか, グエル公園やカサ・ミ ラなどがガウディの作品群という形で世界遺産に登録さ れ，いまも多くの観光客を集めている.

バルセロナといって，もう一つ忘れてはいけないのがピ カソ美術館である. ピカソは青年期をバルセロナで過ごし ており, その当時に描いた「初聖体择領」や「科学と慈愛」 など初期の作品などを見ることができる.

バルセロナは地中海に面しているため, 魚介料理が特に おいしい. パエリアはカタルーニャに南接するバレンシア 州が発祥地であるが，バルセロナでもイカスミのパエリア (図4) やパスタで作るパエリア「フィデゥア (Fideua)」が楽 しめる. 有名なスパークリングワインCAVA はフランスの シャンパーニュ (シャンペン) と同じ方式で作られるため (た だし, 使用されるブドウの品種は異なる), 品質などの点に おいて高く評価されている。筆者も学会会期中はほぼ毎日 CAVAを飲みながらパエリアを楽しんだような記憶がある.

\section{2 米国・オーランド}

来年は米国フロリダ州オーランドの Hilton Orlando Lake Buena Vistaで開催される ${ }^{5)}$.フロリダは年中気候が温暖 で，アメリカ東海岸の寒い地域に居住する人にとっては, クリスマス休みはフロリダで過ごすというのが定番の一つ となっている.

フロリダ州の中でもオーランドはディズニーワールドや ユニバーサルスタジオ, シーワールドなどエンタテインメ 